\title{
Consumer diversity indirectly changes prey nutrient content
}

\author{
Helmut Hillebrand ${ }^{1,4, *}$, Lars Gamfeldtt ${ }^{1,2}$, Per R. Jonsson ${ }^{2}$, Birte Matthiessen ${ }^{3}$ \\ ${ }^{1}$ Botanical Institute, University of Cologne, Gyrhofstrasse 15, 50931 Köln, Germany \\ ${ }^{2}$ Department of Marine Ecology, Tjärnö, University of Gothenburg, 45296 Strömstad, Sweden \\ ${ }^{3}$ Leibniz-Institute for Marine Science, IfM-GEOMAR, Düsternbrooker Weg 20, 24105 Kiel, Germany \\ ${ }^{4}$ Present address: Institut für Chemie und Biologie des Meeres, Carl-von Ossietzky Universität Oldenburg, \\ Schleusenstrasse 1, 26382 Wilhelmshaven, Germany
}

\begin{abstract}
Ecological stoichiometry can be a powerful tool to understand food web consequences of altered biogeochemical cycles as well as consequences of biodiversity loss on biogeochemistry and has proved to be a suitable framework to predict effects of consumers on the nutrient content of their prey. However, predictions from ecological stoichiometry have mainly been tested using single consumer species, whereas in most natural ecosystems several consumer species coexist. We conducted 2 outdoor mesocosm experiments with marine rock pool communities to test whether species richness and species combination of benthic invertebrates affected the nutrient content of periphyton. We independently manipulated 12 different consumer combinations ranging from 0 to 6 (2004) or 0 to 4 (2005) grazer species and measured the biomass and nutrient content of the algae. Grazers included 3 gastropods and 3 crustaceans. In 2005, we additionally analyzed animal nutrient content and $\mathrm{N}$ excretion rate. Algal biomass and C:N ratios decreased in the presence of grazers in both years, indicating that the remaining algae had higher internal N content. Also, both biomass (2004 and 2005) and C:N ratios (only 2004) decreased even further when grazer richness increased. In 2004, significant net diversity effects of grazer richness on periphyton C:N ratios indicated that periphyton $\mathrm{N}$ content under multispecies grazing could not be predicted from the effect of single species. In 2005, significant net diversity effects on C:N ratios were rare, but periphyton $\mathrm{C}: \mathrm{N}$ ratios consistently decreased with increasing grazer excretion rate, indicating that higher nitrogen regeneration by grazers led to higher $\mathrm{N}$ incorporation by algae. The effects of species richness were mainly affected by the presence of one efficient grazer, the gastropod Littorina littorea. Our experiments indicate that non-additive intraguild interactions may qualitatively alter the stoichiometric effects of multispecies consumer assemblages.
\end{abstract}

KEY WORDS: Biodiversity $\cdot$ Ecological stoichiometry $\cdot$ Ecosystem function $\cdot$ Algae $\cdot$ Grazer $\cdot$ Trophic interaction

Resale or republication not permitted without written consent of the publisher

\section{INTRODUCTION}

In addition to the removal of prey biomass, consumers often have indirect effects on the assemblage of their prey such as altering the competitive dominance and coexistence between prey species (Chase et al. 2002, Grover 2002), altering prey behaviour (Peacor $\&$ Werner 2001) or promoting the transformation and bioavailability of nutrients (De Mazancourt et al. 1998). Such indirect effects have received increasing atten- tion in ecological research on trophic interactions (Diehl 1995, Menge 1995, Peacor \& Werner 2001, Hillebrand et al. 2002, Ives et al. 2005), especially in herbivore-plant interactions (Wahl \& Hay 1995, De Mazancourt et al. 1998, Hambäck et al. 2000). The herbivore-mediated regeneration of nutrients has played a pivotal role in the establishment of ecological stoichiometry as a framework to understand trophic interactions through the nutrient composition of the prey and the nutrient demand of the consumer (Sterner \& 
Elser 2002). Comparisons of field data suggest that aquatic and terrestrial plant biomass is characterized by overall lower and more variable content of essential nutrients compared to the biomass of its consumers (Elser \& Hassett 1994, Elser et al. 2000). The rather restricted range of consumer stoichiometry leads to the prediction that nutrients in relative excess compared to the demand are released by the herbivore and thus are available again to plant species (Sterner \& Elser 2002). That is, a diet with high N:P ratios and thus poor Pcontent will lead to retention of $\mathrm{P}$ and release of $\mathrm{N}$ by the grazer. This prediction has been successfully tested in pelagic (MacKay \& Elser 1998, Frost et al. 2004) and benthic ecosystems (Hillebrand \& Kahlert 2001, Frost et al. 2002a, Hillebrand et al. 2004). Conversely, increased plant nutrient content (prey quality) should enhance consumer growth, which also has been shown experimentally (Frost \& Elser 2002, Stelzer \& Lamberti 2002, Urabe et al. 2002).

Considerations of nutrient stoichiometry become highly important in a phase of strong anthropogenic alterations of biogeochemical cycles. The availability of $\mathrm{N}$ has been roughly doubled by humans in recent decades (Vitousek et al. 1997), leading to shifting N:P ratios in many freshwater and coastal marine areas. Shifting resource ratios affect dominance of algal groups in benthic and pelagic communities (Sommer 1994, 1996), as well as trophic transfer and growth on higher trophic levels (Malzahn et al. 2007).

The experimental evidence for the validity of stoichiometric predictions, however, has mainly been assembled focussing on single consumer species, such as single species of crustacean zooplankton (Boersma \& Kreutzer 2002, Urabe et al. 2002, Acharya et al. 2004, DeMott \& Pape 2005) or benthic invertebrates (Frost \& Elser 2002, Stelzer \& Lamberti 2002, Hillebrand et al. 2004). These studies often report direct links between consumer nutrient demand, plant nutrient composition and the effects the consumers have on the prey nutrient content. However, most natural ecosystems harbour a variety of consumer species, which may substantially alter the link between consumer presence and prey nutrient content. Two potential scenarios can be contrasted. First, multispecies assemblages can show intermediate nutrient regeneration compared to the component species. Higher consumer richness will therefore result in a stronger averaging effect. In this scenario, stoichiometric signatures of species traits would disappear in species-rich consumer guilds. Alternatively, the effects of multispecies assemblages may differ from the single species effects by nonaveraging diversity effects. If species differ enough in their demands and assimilation efficiencies for different resources, more consumer species will increase the overall extraction and regeneration of nutrients, for example a strong $\mathrm{P}$-demanding species will profit from the presence of a $\mathrm{N}$-demanding and thus P-recycling species. In this scenario, we expect higher prey nutrient content under multispecies consumption compared to single consumer. To our knowledge, there has been no analysis of an averaging or diversity effect of multiple consumers on stoichiometry of nutrient regeneration and availability.

To test these predictions, we manipulated the identity and richness of grazing invertebrates in 2 outdoor mesocosm experiments and measured their effect on the biomass and nutrient content of the prey assemblage (benthic microalgae). The grazers included 3 littorinid gastropods, 1 amphipod, 1 isopod and 1 shrimp. We contrasted single grazer species treatments (monocultures) to different species combinations (polycultures), and also included a grazer-free control. We measured periphyton biomass and nutrient content to test 4 hypotheses: (1) grazer presence has a significant effect on algal biomass and nutrient content; (2) algal biomass and nutrient content changes with increasing grazer diversity; (3) effects of multispecies grazer assemblages on algal biomass and on algal nutrient content cannot be predicted from monoculture effects (non-additive, or diversity, effect); and (4) observed effects of grazer assemblages on algal nutrient ratios can be predicted from the stoichiometric composition of the grazer assemblage (additive effect). The results of the experiment have the potential to increase our understanding of how consumer species loss may alter the stoichiometry of the prey community.

\section{MATERIALS AND METHODS}

Experimental design. Two experiments were conducted in outdoor mesocosms at the Tjärnö Marine Biological Laboratory on the Swedish west coast $\left(58^{\circ} 54^{\prime} \mathrm{N}, 11^{\circ} 7^{\prime} \mathrm{E}\right)$. Our experimental setup consisted of 48 plastic containers $(40 \times 30 \times 20 \mathrm{~cm})$ which were covered by mesh nets (white fabric $0.039 \mathrm{~g} \mathrm{~cm}^{-2}$ with $1 \mathrm{~mm}$ holes that allowed light penetration of more than $90 \%$, sufficient for algal growth) to prevent emigration and immigration of grazers. The containers were arranged in 2 blocks of 24 aquaria. These blocks were large plastic tubs $(1.2 \times 12 \mathrm{~m})$ filled with saltwater, which reduced variation in temperature and allowed the exchange of water by raising the water level in the tub every $3 \mathrm{~d}$ (for more details about the experimental setup, see Matthiessen et al. 2007). On the Swedish west coast, intertidal rock pools receive water both from the ocean (through waves, splash and occasional floodings) and from rain. The tidal range is approximately $0.3 \mathrm{~m}$, and the main causes of water-level fluctuations are irregular changes in air pressure and wind 
direction. Our choice of regular floodings every $3 \mathrm{~d}$ was a compromise between natural conditions (irregular but sometimes frequent floodings unrelated to tidal cycles) and an easy to follow schedule. The first experiment ran for $5 \mathrm{wk}$ from May to June 2004, the second experiment ran for $8 \mathrm{wk}$ from May to July 2005.

Aquaria in each block were bathed in the same water, potentially raising concerns about the independence of individual aquaria. To explore this, we conducted a short experiment in one tank using an identical setup as in the main experiment, but excluding the animals. A few milliliters of fluorescein was added to one aquarium in one corner of the plastic tub, after which we raised the water level for $3 \mathrm{~h}$, then lowered it again (as in the main experiment). We measured the amount of fluorescein (using a plate reader, Perkin Elmer ${ }^{\circledR}$ Victor 3 1420) in the incubated aquarium and an adjacent one before the incubation, before the water-level rise and 3 times ( 5 min, 1 h, and $20 \mathrm{~h}$ ) after the water was back to its standard level. At no time was the ratio of fluorescein between the adjacent and the incubated aquarium larger than 0.05. It is thus likely that the dependence among aquaria was not sufficiently large as to have a significant effect on the results of the present study.

In both experiments, we manipulated the presence, species richness and species combination of benthic invertebrates in the mesocosms in a replacement series design. Keeping overall abundance constant avoids confounding density and diversity effects, at the cost of having a trade-off between grazer diversity and species density in the experiment. The 6 species of benthic invertebrates in our experiment are all regularly encountered in rock pools in the archipelago around Tjärnö, and all had been shown in preliminary experiments to graze on periphyton (L. Gamfeldt unpubl. data). Table 1 lists the 3 snail (Littorina littorea Linnaeus, L. saxatilis Olivi and L. fabalis Turton) and 3 crustacean species (Gammarus duebenii Liljeborg, Idotea garnulosa Rathke and Palaemon elegans
Rathke) and denotes the species code used throughout the manuscript and the densities in the different experiments.

In 2004, we had 12 different treatments, each of which was replicated 4 times. These treatments consisted of 1 grazer-free control, 6 monocultures of each of the different species, 4 different combinations of 3 species and 1 combination of 6 species (Table 1). The 4 different combinations of 3 species were randomly selected (ABC, ABD, CEF and DEF). In 2005, we again constructed 12 different treatments with 4 replicates each. Here we opted to focus on the 4 most abundant grazer species (Table 1) and manipulated all 4 species in monoculture, all 6 possible combinations of 2 species, all 4 species combined and a grazer-free control. Both experiments used a replacement series design; the abundance of each species was adjusted according to the diversity levels (Table 1).

Sampling and analysis. Periphyton biomass and nutrient content were monitored on unglazed ceramic tiles, which were placed in the aquaria at the onset of the experiment. At the termination of the experiments, periphyton was scraped off the tiles using razorblades and filtered onto pre-combusted GF/F filters. Filtered periphyton $\mathrm{C}$ and $\mathrm{N}$ were subsequently measured in a Fisons CN-analyzer. Periphyton biomass was determined as $\mu \mathrm{g} \mathrm{C} \mathrm{cm}^{-2}$, whereas periphyton nutrient stoichiometry was given as the molar C:N ratio. We focused on $\mathrm{N}$ dynamics, as C:N ratios were high (2004: 14.62; 2005: 15.22) and N:P ratios were low in the ungrazed treatments, which has been shown to be indicative of N limitation (Hillebrand \& Sommer 1999).

In 2005, we additionally addressed the grazer nutrient content by randomly picking 6 individuals of each of the 4 species and measuring their body nutrient composition. Animals were dried for $24 \mathrm{~h}$ at $60^{\circ} \mathrm{C}$. For the C:N measurements, the dried animal was ground and an aliquot was directly measured with a CN-analyzer (see above). $\mathrm{C}$ and $\mathrm{N}$ were then given as \% dry mass and used to calculate $\mathrm{C}: \mathrm{N}$ ratios. $\mathrm{N}$ excretion

Table 1. Invertebrate species used in the mesocosm study, including species name, class (G: Gastropoda; C: Crustacea) and code. Starting density is the number of individuals used per aquarium for each monoculture mesocosm in 2004 and 2005 . For polycultures, the densities were divided by number of species in the treatment. Mean molar ratios of C:N in the animal tissue and the individual ammonium excretion rate were measured in 2005 only $( \pm$ SE)

\begin{tabular}{|lcccccc|}
\hline Species & Class & Code & \multicolumn{2}{c|}{$\begin{array}{c}\text { Starting density } \\
2005\end{array}$} & C:N molar & $\begin{array}{c}\text { Excretion rate } \\
\left(\mu \mathrm{mol} \mathrm{N} \mathrm{ind}^{-1} \mathrm{~d}^{-1}\right)\end{array}$ \\
\hline Palaemon elegans Rathke & $\mathrm{C}$ & $\mathrm{A}$ & 6 & & \\
Littorina littorea L. & $\mathrm{G}$ & $\mathrm{B}$ & 21 & 14 & $5.64 \pm 0.83$ & $0.34 \pm 0.45$ \\
Idotea granulosa Rathke & $\mathrm{C}$ & $\mathrm{C}$ & 25 & 34 & $5.41 \pm 0.12$ & $2.03 \pm 0.73$ \\
Littorina saxatilis Olivi & $\mathrm{G}$ & $\mathrm{D}$ & 22 & 15 & $4.74 \pm 0.40$ & $0.73 \pm 0.69$ \\
Gammarus duebenii Lilj. & $\mathrm{C}$ & $\mathrm{E}$ & 32 & 44 & $5.07 \pm 0.18$ & $0.58 \pm 0.23$ \\
Littorina fabalis Turton & $\mathrm{G}$ & $\mathrm{F}$ & 25 & & & \\
\hline
\end{tabular}


rates were measured by transferring individual specimens for all 4 species used in 2005 into beakers with $200 \mathrm{ml}$ filtered seawater. After $24 \mathrm{~h}$ we measured ammonium content in each of the beakers (according to Grasshoff et al. 1983) and - by comparison to an animal-free blank treatment-calculated the excreted amount per individual (6 replicates per species). For the species mixtures in the 2005 experiment, we calculated the average community $\mathrm{C}: \mathrm{N}$ ratio and the total community ammonium excretion rate using the species-specific information on $\mathrm{C}: \mathrm{N}$ ratios and excretion rates. The averages were calculated as weighted averages, i.e. the species specific information was entered in proportion to the final abundance of each of the 4 grazer species in each treatment and divided by the total abundance. These calculations can be seen as null expectations, assuming that the presence of other grazers did not change the $\mathrm{C}: \mathrm{N}$ ratio and excretion rate of each grazer species.

Statistical analysis. Since the 2 experiments differed in duration and species composition as well as slightly in ambient environmental conditions (temperature, cloudiness, etc.), they were analysed separately. All comparisons between the experiments are thus qualitative. The 2 blocks (tubs) had no significant effect on any of the response variables and were therefore omitted from the statistical analysis. For periphyton biomass (total C) and stoichiometry (C:N), a 1-way ANOVA was conducted with species combination as a factor. To test Hypotheses 1 and 2 we performed 3 consecutive planned contrasts: (1) between grazer absence and grazer presence testing Hypothesis 1 (0 against 1 to 6 species); (2) between monocultures and polycultures testing Hypothesis 2 (1 against 3 and 6 species in 2004 or against 2 and 4 species in 2005); and (3) between 3 and 6 species or 2 and 4 species. All response variables were log-transformed to achieve homogeneity of variance.

To test whether results for polycultures differed from what could be expected from monoculture performance (Hypothesis 3), net diversity effects (NDE) were calculated (Loreau \& Hector 2001). NDE were developed to estimate the difference between observed and expected biomass yield in multispecies assemblages within one trophic level. We used a similar rationale here to measure the difference between observed values (algal biomass and stoichiometry) in multispecies grazer assemblages and expected values calculated from monocultures. When algal biomass is reduced to $x \mu \mathrm{g} C$ by species A and $y \mu g$ C by species B, the replacement series combination of $\mathrm{A}$ and $\mathrm{B}$ is expected to result in $0.5(x+y) \mu \mathrm{g} C$. Thus, for each species combination of 3 and 6 grazer species, the expected periphyton biomass and nutrient content in polycultures was calculated from the monocultures of the grazer species involved in that combination. The NDE for biomass or nutrient ratio is given by the difference between observed and expected values. Significant deviation of NDE from 0 indicates that the species combination had an effect on the response variable beyond a mere averaging effect. The significance of this deviation was tested with $t$-tests on square-root transformed NDE values.

Finally, we used correlations between calculated grazer $\mathrm{N}$ excretion rates, grazer $\mathrm{C}: \mathrm{N}$ ratios and periphyton $\mathrm{C}: \mathrm{N}$ ratios to test whether grazer effects on periphyton can be predicted from their stoichiometry (Hypothesis 4).

\section{RESULTS}

\section{4 experiment}

Periphyton biomass was significantly affected by the grazer manipulation (ANOVA, $F_{11,36}=25.48, \mathrm{p}<$ $0.0001)$. The lowest periphyton biomass was observed in the treatments containing Littorina littorea $(\mathrm{B}, \mathrm{ABC}$, $\mathrm{ABD})$, whereas the highest occurred in treatments containing no grazer or L. fabalis (F, CEF, DEF) (Fig. 1A). Planned contrasts showed a significant reduction of biomass when grazers were present (0 against grazer presence, $F=18.6, \mathrm{p}=0.0001$ ), and a further significant reduction when $>1$ species was present (1 against 3 and 6 species, $F=17.19, \mathrm{p}=0.0002$ ). Treatments with 3 and 6 species did not differ in periphyton biomass $(F=1.94, \mathrm{p}=0.17)$.

Grazer presence and species combination affected periphyton stoichiometry significantly (ANOVA, $\left.F_{11,36}=2.14, \mathrm{p}=0.0429\right)$. The highest $\mathrm{C}: \mathrm{N}$ ratios were observed in the absence of grazers (Fig. 1B); these ratios were significantly higher than in the grazed treatments (planned contrast, $F=5.52, \mathrm{p}=0.0243$ ). C:N ratios were further reduced in polycultures compared to monocultures $(F=5.27, \mathrm{p}=0.0277)$, but were not different between 3 and 6 species treatments $(F=0.01$, $\mathrm{p}=0.9397)$.

NDE on periphyton biomass were overall significantly negative $(t=-3.00, \mathrm{~N}=20, \mathrm{p}=0.0073)$, indicating that more diverse grazer assemblages reduced periphyton biomass more than could be expected from monoculture performance. This strong effect of diversity was based on the combinations $\mathrm{ABC}, \mathrm{ABD}$ and ABCDEF, i.e. those combinations containing both Littorina littorea and Palaemon elegans (Fig. 1C). L. littorea was the only one of these 2 species that had large negative effects on algal biomass in monoculture, suggesting that the diversity effect was mostly due to selection effects for this gastropod. Corroborating the reduction in $\mathrm{C}: \mathrm{N}$ ratio with increasing grazer richness, 

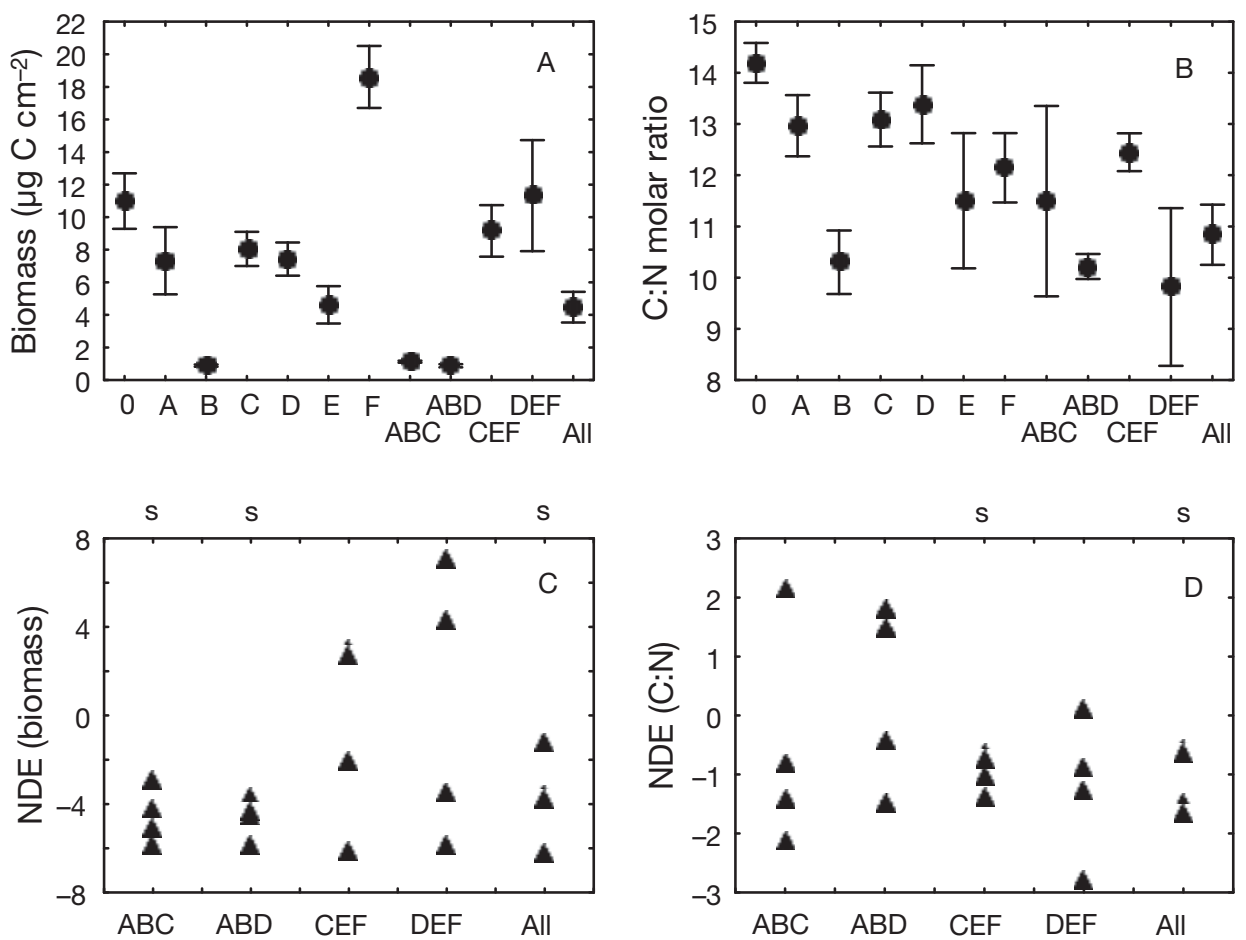

Fig. 1. 2004 experiment. (A) Periphyton biomass and (B) C:N ratio at different grazer treatment levels (mean \pm SE). Grazer-free controls are denoted by 0 , followed by 6 monocultures, 4 species combinations of 3 species and 1 combination containing all 6 species. Net diversity effects (NDE) of multispecies grazer assemblages on (C) periphyton biomass and (D) C:N ratios. Values are square-root transformed (with sign preserved). s: significant difference of the NDE from $0(t$-test, $\mathrm{n}=4, \mathrm{p}<0.05)$. For species codes see Table 1

NDE for C:N ratios were significantly negative overall $(t=-2.43, \mathrm{~N}=20, \mathrm{p}=0.025)$. Negative NDE were pronounced in the 3-species combination CEF (Idotea granulosa, Gammarus duebenii and L. fabalis) and in the 6-species combination (Fig. 1D). The overall negative NDE on C:N ratios indicates clearly that multispecies grazer assemblages increased the relative $\mathrm{N}$ content of periphyton more than could be predicted from grazer monocultures.

\section{5 experiment}

As in 2004, periphyton biomass was significantly affected by the grazer manipulation (ANOVA, $F_{11 ; 36}=$ 8.52, p < 0.0001) (Fig. 2A). Planned contrasts showed a significant reduction of biomass when grazers were present ( 0 against grazer presence, $F=46.8, p<$ 0.0001 ), and a further significant reduction when $>1$ species was present ( 1 against 2 and 4 species, $F=$ $4.79, \mathrm{p}=0.035)$. Treatments with 2 and 4 grazer species did not differ in periphyton biomass $(F=1.42, \mathrm{p}=$ 0.240).

Corroborating the findings from 2004, grazer presence and species combination affected periphyton stoichiometry significantly (ANOVA, $F_{11 ; 36}=2.96, \mathrm{p}=$ 0.0069). The highest $C: N$ ratios were observed in the absence of grazers (Fig. 2B); these ratios were significantly higher than in the grazed treatments (planned contrast, $F=10.31, \mathrm{p}=0.0028)$. C:N ratios were not significantly reduced in polycultures compared to monocultures $(F=1.17, \mathrm{p}=0.286)$.

The NDE on periphyton biomass was overall significantly negative $(t=-3.87, \mathrm{~N}=28, \mathrm{p}=0.0006)$, indicating that more diverse grazer assemblages reduced periphyton biomass more than could be expected from monoculture performance. This strong effect of diversity was based on the combinations $\mathrm{BC}$ and $\mathrm{BD}$, both containing Littorina littorea (Fig. 2C). NDE for C:N ratios were negative, although the difference from 0 was marginally non-significant $(t=-1.91, \mathrm{~N}=28, \mathrm{p}=$ 0.066). Negative NDE were significant in the 2-species combination BE (L. littorea and Gammarus duebenii) (Fig. 2D).

Grazers with high $\mathrm{C}: \mathrm{N}$ ratios tended to excrete less ammonium with the prominent exception of Idotea granulosa, which had extraordinarily high excretion rates (Table 1). In contrast to the other species, I. granulosa suffered massive mortality under the experiment in 2005. Therefore, I. granulosa had a minimal effect 

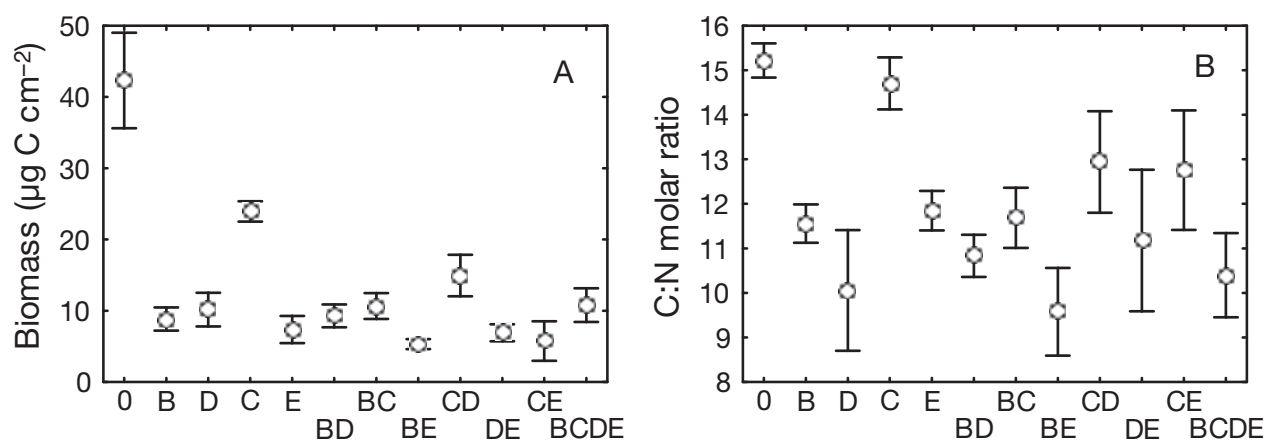

S S
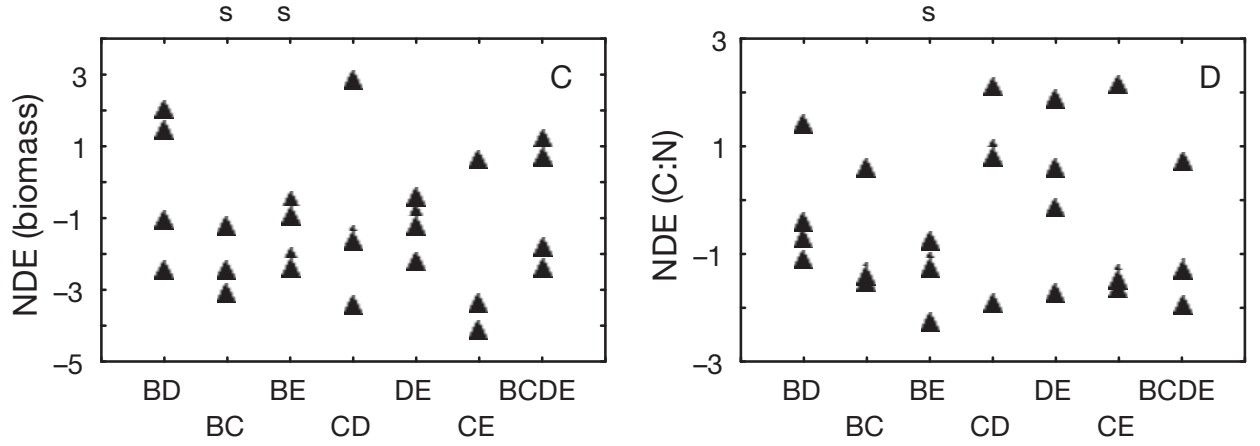

Fig. 2. 2005 experiment. (A) Periphyton biomass and (B) C:N ratio at different grazer treatment levels (mean \pm SE). Grazer-free controls are denoted by 0 , followed by 4 monocultures, 6 combinations of 2 species and 1 combination containing all 4 species. Net diversity effects (NDE) of multispecies grazer assemblages on (C) periphyton biomass and (D) C:N ratios. Values are squareroot transformed (with sign preserved). s: significant difference of the NDE from 0 ( $t$-test, $\mathrm{n}=4, \mathrm{p}<0.05)$. For species codes see Table 1

on grazing and nutrient regeneration, which was mainly driven by the other 3 species, showing coherence between $\mathrm{N}$ content and excretion rate. Consequently, we found a significant negative correlation $(\mathrm{r}=-0.628, \mathrm{p}<0.001)$ between the abundanceweighted grazer $\mathrm{C}: \mathrm{N}$ ratio and the estimated excretion rate of the assemblage (Fig. 3A). Thus, grazers with lower $\mathrm{N}$ content (higher C:N ratios) released less $\mathrm{N}$. Periphyton nutrient content significantly reflected the calculated excretion rates: the more ammonium an assemblage was predicted to excrete, the lower was the periphyton $\mathrm{C}: \mathrm{N}$ ratio $(\mathrm{r}=-0.323, \mathrm{p}=0.037)$ (Fig. 3B).

\section{DISCUSSION}

The manipulation of grazer presence and grazer species composition had strong effects on the biomass and nutrient stoichiometry of the periphyton. Grazer presence reduced periphyton biomass and $\mathrm{C}: \mathrm{N}$ ratios, i.e. resulted in high relative $\mathrm{N}$ content in the remaining periphyton (supporting Hypothesis 1). Such positive effects of consumers on prey nutrient content have frequently been observed in littoral food webs (Rosemond
1993, Hillebrand \& Kahlert 2001, Frost et al. 2002a, Hillebrand et al. 2004). Several mechanisms would explain the increased concentration of nutrients in grazed periphyton (McCormick \& Stevenson 1991, Hillebrand \& Kahlert 2001, Frost et al. 2002b, Hillebrand et al. 2008): grazers may promote the uptake of available nutrients by increasing hydrodynamic mixing above the periphyton or by removing nutrient-poor detritus, or grazers may increase the availability of nutrients by excretion or egestion. Hillebrand et al. (2008) discuss these mechanisms in more detail.

Grazer richness and species combination altered the effects of grazers on periphyton biomass and nutrient content (supporting Hypothesis 2). Periphyton biomass (measured as C) was reduced more by multispecies grazer assemblages than by single species in both years (see also Matthiessen et al. 2007). The periphyton biomass under multispecies grazing was significantly lower than could be expected from the performance under grazer monocultures, i.e. NDE were consistently negative. The increase in consumption with increasing consumer diversity has also been observed for experiments with a variety of aquatic consumer-prey interactions, such as epiphyte-grazing invertebrates on eelgrass (Duffy et al. 2003), suspen- 

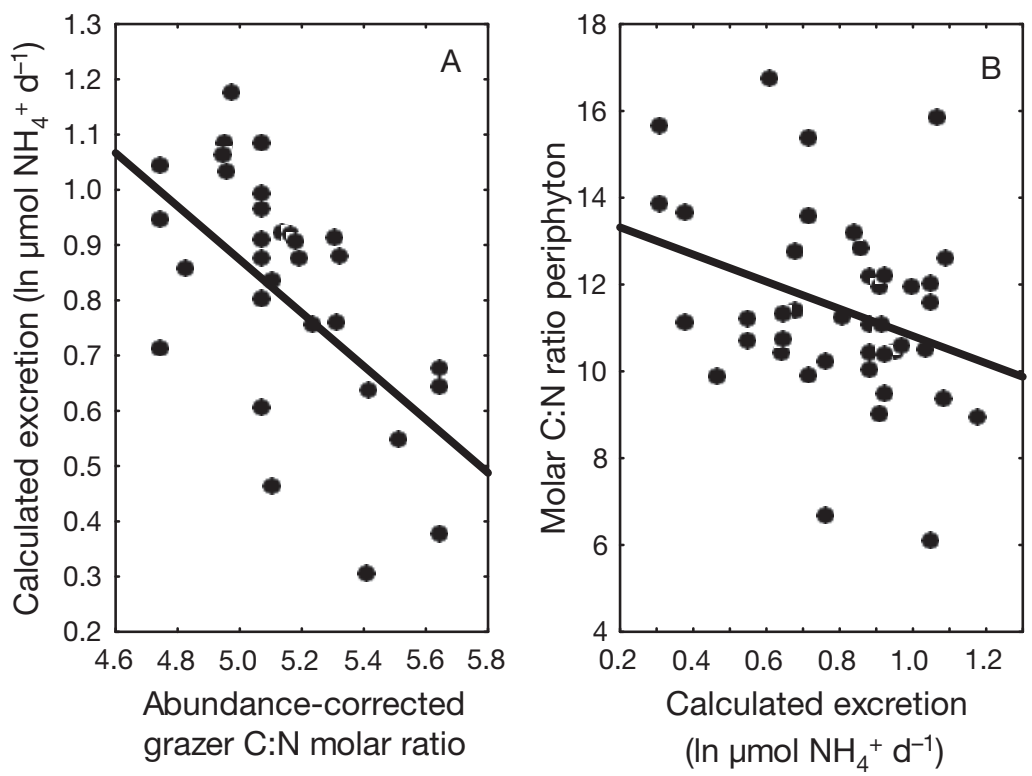

Fig. 3. (A) Relationship between the body C:N ratio of grazer assemblages (calculated from mean body $\mathrm{C}: \mathrm{N}$ ratio and final abundance in each treatment) and grazer ammonium excretion rate (calculated from individual excretion rate and final abundance). (B) Relationship between the grazer ammonium excretion rate and measured periphyton $\mathrm{C}: \mathrm{N}$ ratio

sion-feeding stream invertebrates (Cardinale et al. 2002), shredders in streams (Jonsson et al. 2002) and algivorous ciliates (Gamfeldt et al. 2005). It is especially evident that the gastropod Littorina littorea had a strong negative effect on algal biomass. All combinations with this species present were associated with lower levels of $\mathrm{C}$ compared to the other combinations (Fig. 1A). Effects of multiple grazer assemblages with L. littorea generally differed from those of the monocultures as shown by negative NDE (Fig. 1C), thereby supporting Hypothesis 3 that the effects were nonadditive.

Regarding periphyton stoichiometry, the C:N ratio was affected by grazer presence and grazer composition. Overall, C:N ratios were high in the absence of grazers, which indicates limited supply of $\mathrm{N}$ to the periphyton (Hillebrand \& Sommer 1999). Periphyton $\mathrm{C}: \mathrm{N}$ ratios significantly decreased when grazers were present (in both years) and when grazer assemblages became more diverse (in 2004 only). That is, the relative $\mathrm{N}$ content of the periphyton increased in the presence of grazers and increased further with increasing grazer diversity. Whereas positive effects of grazer presence on relative algal nutrient content are frequently reported (Hillebrand et al. 2008), the observation that more grazer species further enhance nutrient content (in 2004) is, to our knowledge, an unprecedented result. Moreover, we found significant NDE on periphyton C:N ratios in 2004 and marginally non- significant NDE in 2005, which indicates that periphyton $\mathrm{C}: \mathrm{N}$ ratios in multispecies treatments was not an intermediate of the values observed in species monocultures (supporting Hypothesis 3). The results indicate that the effect of grazer richness on the $\mathrm{C}: \mathrm{N}$ ratio was partly affected by the presence of Littorina littorea, but this identity effect was less clear than it was for biomass.

Unfortunately, we only have information on the excretion of the different grazer species in 2005, whereas the larger diversity effect on C:N ratios was observed in 2004. In 2005, we can show that the enhanced excretion of ammonium by consumers is reflected by enhanced $\mathrm{N}$ content of the periphyton, which supports Hypothesis 4. Moreover, assemblages with higher than expected grazing impact on periphyton biomass (more negative NDE on biomass) also reduced C:N ratios more (more negative NDE on $\mathrm{C}: \mathrm{N}$ ratios), indicated by a positive correlation between NDE on biomass and NDE on C:N ratios $(\mathrm{r}=0.49, \mathrm{p}=0.007)$.

Thus, in 2005, the grazer effect on periphyton $C: N$ was mainly a consequence of individual $\mathrm{N}$ excretion and more efficient biomass removal by more speciesrich grazer assemblages. Excretion by grazers has been shown to enhance nutrient uptake and content of periphytic algae (Evans-White \& Lamberti 2005, Liess \& Haglund 2007). Higher biomass removal can also increase the bulk periphyton $\mathrm{N}$ content by different mechanisms (Hillebrand et al. 2008) such as removing N-poor detritus, shifting species composition, promoting mixing in the boundary layers or changing the relationship between available nitrogen concentrations and living algal biomass. In 2005, we mainly saw an averaging effect of multiple grazer species on periphyton stoichiometry, whereas deviations from averaging were weak and marginally non-significant.

For 2004, we lack excretion data, however, we can show that the diversity effects on $\mathrm{C}: \mathrm{N}$ ratios are not simply driven by higher consumption, as there was no correlation between NDE on biomass and C:N ratio, respectively $(r=0.08, p=0.753)$. Thus, even without the excretion data, we suggest that in 2004 we mainly see a diversity effect on nutrient regeneration. Higher species richness of consumers may increase regeneration rates by increasing the probability of including a species with very high excretion rates, which would represent a selection effect as discussed in the frame- 
work of biodiversity effects on ecosystem functioning (Loreau 2000). Nutrient turnover may also increase with increasing consumer richness, when ingested food types differ between species and higher richness concurs with more nutrients made available to the algae. Such a mechanism would be especially strong when consumers shift resources from one group within the periphyton (bacteria, protozoans, meiofauna) to another (algae) by omnivory or intraguild predation (Vanni \& Layne 1997, Hillebrand et al. 2002, Geddes \& Trexler 2003), or when grazers with different $\mathrm{N}$ requirements result in a temporal averaging of high $\mathrm{N}$ regeneration. This pathway would represent a complementary effect as discussed in the framework of biodiversity effects on ecosystem functioning (Loreau 2000). In our 2004 experiment, NDE were related to a single species, Littorina littorea, which, if present, strongly reduced periphyton $\mathrm{C}: \mathrm{N}$ ratios. This strongly indicates that selection effects were important for the observed diversity effect.

In conclusion, periphyton nutrient content was strongly influenced by grazer presence and species composition in both years. In the 2004 experiment, we observed a significant diversity effect, which was mainly based on the fact that higher grazer diversity enhanced the probability of including Littorina littorea, which enhanced periphyton $\mathrm{N}$ content. In the 2005 experiment, diversity effects were smaller and the nutrient content in periphyton under multispecies grazing reflected well the predicted effects from $\mathrm{N}$ excretion. This finding has important consequence for the stoichiometric framework when extrapolating from single consumer model systems to highly diverse systems observed in many coastal areas. Using a stoichiometrically explicit model restricted to one grazer species, Daufresne \& Loreau (2001) showed that herbivore presence can induce shifts from $\mathrm{N}$ to $\mathrm{P}$ limitation in their plant prey given a set of conditions on N:P supply ratios and differential affinity of animals and plants for $\mathrm{N}$ and $\mathrm{P}$, respectively. They concluded that determination of plant nutrient limitation is influenced by complex dynamics comprising the N:P ratios of different compartments (dissolved nutrients, plants and animals) and the direct interactions between animals and plants.

Understanding ecological stoichiometry in multispecies frameworks is an urgent task, necessary to understand food web consequences of altered biogeochemical cycles as well as the consequences of altered biodiversity on biogeochemistry. The potential consequences of altered biodiversity and biogeochemistry have rarely, if ever, been analyzed together, as both aspects are dealt with in different ecological subdisciplines. A recent simulation study strongly indicated that loss of fish species in an African lake could strongly alter the internal recycling of $\mathrm{N}$ and $\mathrm{P}$ in the lake (McIntyre et al. 2007). Likewise, our results emphasize that consumer species identity and species composition can have consequences for the relative availability of nutrients for autotrophs.

Acknowledgements. J. Wallén, J. Ericson, F. Ljunghager and F. Lindgren helped sample the organisms. C and N samples were measured by T. Hansen, IfM-GEOMAR, with the help of J. Harloff. The experiment was funded by 2 German Research Foundation projects to H.H. (contracts Hi848/1-1 and Hi848/ 4-1), by the Swedish Environmental Protection Agency through the Marine Biodiversity Patterns and Processes program (L.G.), and by the Swedish Research Council for Enviroment, Agricultural Sciences and Spatial Planning through contract 215/2006-2096 (P.R.J.). Additionally, the travel necessary to perform the experiment was funded by a mutual exchange program funded by the German Academic Exchange Service to H.H. (contract D/04/04738) and the Swedish Foundation for International Cooperation in Research and Higher Education to P.R.J. (contract Dnr 03/120). The manuscript profited from comments by L. BenedettiCecchi and 3 anonymous reviewers.

\section{LITERATURE CITED}

Acharya K, Kyle M, Elser JJ (2004) Biological stoichiometry of Daphnia growth: an ecophysiological test of the growth rate hypothesis. Limnol Oceanogr 49:656-665

Boersma M, Kreutzer C (2002) Life at the edge: Is food quality really of minor importance at low quantities? Ecology 83: 2552-2561

Cardinale BJ, Palmer MA, Collins SL (2002) Species diversity enhances ecosystem functioning through interspecific facilitation. Nature 415:426-429

- Chase JM, Abrams PA, Grover JP, Diehl S and others (2002) The interaction between predation and competition: a review and synthesis. Ecol Lett 5:302-315

Daufresne T, Loreau M (2001) Plant-herbivore interactions and ecological stoichiometry: When do herbivores determine plant nutrient limitation? Ecol Lett 4:196-206

De Mazancourt C, Loreau M, Abbadie L (1998) Grazing optimization and nutrient cycling: When do herbivores enhance plant production? Ecology 79:2242-2252

> DeMott WR, Pape BJ (2005) Stoichiometry in an ecological context: testing for links between Daphnia P-content, growth rate and habitat preference. Oecologia 142:20-27

Diehl S (1995) Direct and indirect effects of omnivory in a littoral lake community. Ecology 76:1727-1740

Duffy JE, Richardson JP, Canuel EA (2003) Grazer diversity effects on ecosystem functioning in seagrass beds. Ecol Lett 6:637-645

Elser JJ, Hassett RP (1994) A stoichiometric analysis of the zooplankton-phytoplankton interaction in marine and freshwater ecosystems. Nature 370:211-213

Elser JJ, Fagan WF, Denno RF, Dobberfuhl DR and others (2000) Nutritional constraints in terrestrial and freshwater food webs. Nature 408:578-580

Evans-White MA, Lamberti GA (2005) Grazer species effectson epilithon nutrient composition. Freshw Biol 50: 1853-1863

Frost PC, Elser JJ (2002) Growth responses of littoral mayflies to the phosphorus content of their food. Ecol Lett 5: $232-240$ 
Frost PC, Elser JJ, Turner MA (2002a) Effects of caddisfly grazers on the elemental composition of epilithon in a boreal lake. J N Am Benthol Soc 21:54-63

Frost PC, Stelzer RS, Lamberti GA, Elser JJ (2002b) Ecological stoichiometry of trophic interactions in the benthos: understanding the role of $\mathrm{C}: \mathrm{N}: \mathrm{P}$ ratios in lentic and lotic habitats. J N Am Benthol Soc 21:515-528

Frost PC, Xenopoulos MA, Larson JH (2004) The stoichiometry of dissolved organic carbon, nitrogen, and phosphorus release by a planktonic grazer, Daphnia. Limnol Oceanogr 49:1802-1808

Gamfeldt L, Hillebrand H, Jonsson PR (2005) Species richness changes across two trophic levels simultaneously affect prey and consumer biomass. Ecol Lett 8:696-703

Geddes P, Trexler JC (2003) Uncoupling of omnivore-mediated positive and negative effects on periphyton mats. Oecologia 136:585-595

Grasshoff K, Ehrhardt M, Kremling K (1983) Methods of seawater analysis, 2nd edn. Verlag Chemie, Weinheim

> Grover JP (2002) Stoichiometry, herbivory and competition for nutrients: simple models based on planktonic ecosystems. J Theor Biol 214:599-618

Hambäck PA, Agren J, Ericson L (2000) Associational resistance: insect damage to purple loosestrife reduced in thickets of sweet gale. Ecology 81:1784-1794

Hillebrand H, Kahlert M (2001) Effect of grazing and nutrient supply on periphyton biomass and nutrient stoichiometry in habitats of different productivity. Limnol Oceanogr 46:1881-1898

Hillebrand H, Sommer U (1999) The nutrient stoichiometry of benthic microalgal growth: Redfield proportions are optimal. Limnol Oceanogr 44:440-446

Hillebrand H, Kahlert M, Haglund AL, Berninger UG, Nagel S, Wickham S (2002) Control of microbenthic communities by grazing and nutrient supply. Ecology 83:2205-2219

Hillebrand H, de Montpellier G, Liess A (2004) Effects of macrograzers and light on periphyton stoichiometry. Oikos 106:93-104

Hillebrand H, Frost P, Liess A (2008) Ecological stoichiometry of indirect grazer effects on periphyton nutrient content. Oecologia 155:619-630

Ives AR, Cardinale BJ, Snyder WE (2005) A synthesis of subdisciplines: predator-prey interactions, and biodiversity and ecosystem functioning. Ecol Lett 8:102-116

Jonsson M, Dangles O, Malmqvist B, Guerold F (2002) Simulating species loss following perturbation: assessing the effects on process rates. Proc R Soc Lond B Biol Sci 269:1047-1052

Liess A, Haglund AL (2007) Periphyton responds differentially to nutrients recycled in dissolved or faecal pellet form by the snail grazer Theodoxus fluviatilis. Freshw Biol 52:1997-2008

Editorial responsibility: Lisandro Benedetti-Cecchi, Pisa, Italy
Loreau M (2000) Biodiversity and ecosystem functioning: recent theoretical advances. Oikos 91:3-17

Loreau M, Hector A (2001) Partitioning selection and complementarity in biodiversity experiments. Nature 412:72-76

MacKay NA, Elser JJ (1998) Nutrient recycling by Daphnia reduces $\mathrm{N}_{2}$ fixation by cyanobacteria. Limnol Oceanogr 43:347-354

Malzahn AM, Aberle N, Clemmesen C (2007) Nutrient limitation of primary producers affects planktivorous fish condition. Limnol Oceanogr 52:2062-2071

> Matthiessen B, Gamfeldt L, Jonsson PR, Hillebrand H (2007) Effects of grazer richness and composition on algal biomass in a closed and open marine system. Ecology 88: 178-187

McCormick PV, Stevenson RJ (1991) Grazer control of nutrient availability in the periphyton. Oecologia 86:287-291

McIntyre PB, Jones LE, Flecker AS, Vanni MJ (2007) Fish extinctions alter nutrient recycling in tropical freshwaters. Proc Natl Acad Sci USA 104:4461-4466

Menge BA (1995) Indirect effects in marine rocky intertidal interaction webs: patterns and importance. Ecol Monogr 65:21-74

> Peacor SD, Werner EE (2001) The contribution of trait-mediated indirect effects to the net effects of a predator. Proc Natl Acad Sci USA 98:3904-3908

Rosemond AD (1993) Interactions among irradiance, nutrients, and herbivores constrain a stream algal community. Oecologia 94:585-594

> Sommer U (1994) Are marine diatoms favoured by high Si:N ratios? Mar Ecol Prog Ser 115:309-315

Sommer U (1996) Nutrient competition experiments with periphyton from the Baltic Sea. Mar Ecol Prog Ser 140: 161-167

Stelzer RS, Lamberti GA (2002) Ecological stoichiometry in running waters: periphyton chemical composition and snail growth. Ecology 83:1039-1051

Sterner RW, Elser JJ (2002) Ecological stoichiometry. Princeton University Press, Princeton, NJ

Urabe J, Kyle M, Makino W, Yoshida T, Andersen T, Elser JJ (2002) Reduced light increases herbivore production due to stoichiometric effects of light/nutrient balance. Ecology 83:619-627

Vanni MJ, Layne CD (1997) Nutrient recycling and herbivory as mechanisms in the 'top-down' effect of fish on algae in lakes. Ecology 78:21-40

Vitousek PM, Aber JD, Howarth RW, Likens GE and others (1997) Human alterations of the global nitrogen cycle: sources and consequences. Ecol Appl 7:737-750

Wahl M, Hay ME (1995) Associational resistance and shared doom: effects of epibiosis on herbivory. Oecologia 102: $329-340$

Submitted: July 2, 2008; Accepted: January 19, 2009

Proofs received from author(s): March 26, 2009 